\title{
Erratum to: Neurodynamics of Mind: The Arrow Illusion of Conscious Intentionality as Downward Causation
}

\author{
Joaquín Barutta • Ezequiel Gleichgerrcht • \\ Carlos Cornejo • Agustín Ibáñez
}

Published online: 20 April 2010

(C) Springer Science+Business Media, LLC 2010

\section{Erratum to: Integr Psych Behav \\ DOI 10.1007/s12124-010-9117-8}

The first institution of the author Agustín Ibanez was inadvertently not published in the original article. The missing institutional affiliation information of this author is Laboratory of Neuroscience, Universidad Diego Portales, Santiago de Chile, see below.

The online version of the original article can be found under at http://dx.doi.org/10.1007/s12124-010-9117-8.

\footnotetext{
A. Ibáñez $(\bowtie)$

Laboratory of Experimental Psychology \& Neurosciences, Institute of Cognitive Neurology (INECO) and Institute of Neuroscience, Favaloro University, Castex 3293, CP 1425 Buenos Aires, Argentina e-mail: aibanez@neurologiacognitiva.org

URL: http://www.neurologiacognitiva.org

E. Gleichgerrcht • A. Ibáñez

Laboratory of Experimental Psychology \& Neuroscience, Institute of Cognitive Neurology, INECO, Buenos Aires, Argentina
}

\section{A. Ibáñez}

National Scientific and Technical Research Council (CONICET), Buenos Aires, Argentina

\section{J. Barutta}

Laboratory of Epistemology and History of Medicine (LEPHIM), Instituto Universitario del Hospital Italiano de Buenos Aires, Buenos Aires, Argentina

\section{Cornejo}

Escuela de Psicología, Pontificia Universidad Católica de Chile, Santiago, Chile

\section{A. Ibáñez}

Laboratory of Neuroscience, Universidad Diego Portales, Santiago de Chile, Chile 